First publ. in: Toxicology letters 131 (2002), 1/2, pp. 51-63

\title{
Morphological sex reversal upon short-term exposure to endocrine modulators in juvenile fathead minnow (Pimephales promelas)
}

\author{
Melanie Zerulla a,*, R. Länge ${ }^{\text {a }}$, T. Steger-Hartmann ${ }^{a}$, G. Panter ${ }^{\text {, }}$, \\ T. Hutchinson ${ }^{\mathrm{c}}$, D.R. Dietrich ${ }^{\mathrm{d}}$ \\ ${ }^{\text {a }}$ Schering AG, Experimental Toxicology, Berlin, Germany

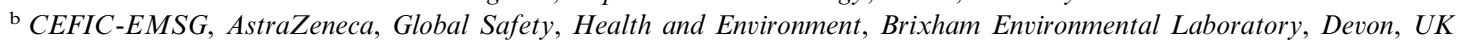 \\ ${ }^{c}$ AstraZeneca, Global Safety, Health and Environment, Brixham Environmental Laboratory, Devon, UK \\ d Environmental Toxicology, University of Konstanz, Konstanz, Germany
}

\begin{abstract}
Indications of effects on fish endocrine system have been noted when exposed to effluents of sewage treatment plants and subsequently in the receiving surface waters. For screening purposes, the concentration of vitellogenin (VTG) in plasma is employed to detect potential exposure of fish, to (anti-)estrogenic substances. However, little is known about the variability of VTG determinations and morphological endpoints (secondary sexual characteristics) in fish under exposure conditions employing compounds with hormonal activity other than estrogens. An in vivo test system was established to study the effects of methyltestosterone (MT, a potential model androgen) and fadrozole (F, an aromatase inhibitor) as well as the combination of MT and F on juvenile, sexually undifferentiated fathead minnows (Pimephales promelas). Fish were exposed to those compounds continuously in the (nominal) $\mu \mathrm{g} / 1 \mathrm{range}$ (MT, 10, 50 and $100 \mu \mathrm{g} / \mathrm{l} ; \mathrm{F}, 25,50,100 \mu \mathrm{g} / \mathrm{l}$; MT + F, $10 \mu \mathrm{g}$ MT per $1+50 \mu \mathrm{g}$ F per 1), for 14 days (MT $+\mathrm{F}$ ) or 21 days (MT and F) using a flow-through system. The concentration of VTG and the expression of VTG mRNA was determined using whole body homogenates in an enzyme linked immunosorbant assay (ELISA) or reverse transcription-polymerase chain reaction (RT-PCR), respectively. Exposure to MT alone led to de novo mRNA expression as well as up to a four-fold increase of VTG. F had no effect on the VTG mRNA expression and VTG protein synthesis. The combination of MT and F had no effect on VTG concentrations, however, this produced a strong masculinisation of the juvenile fish, e.g. after 13 days of exposure $100 \%$ of the fish showed typical male sex characteristics, e.g. formation of nose tubercles and pigmentation of the dorsal fin. The above findings suggest that in fish MT may be aromatised to an estrogen. F, on the other hand, inhibits testosterone aromatisation. Consequently, the combination of MT and F strongly morphologically masculinised the juvenile fathead minnows. VTG detection at the mRNA and protein level is a sensitive parameter, however, it does not provide for any information regarding the baseline 'estrogenicity' of a given parent compound.
\end{abstract}

* Corresponding author. Tel.: + 49-30-4681-5763; fax: + 49-30-4681-5091.

E-mail address: melanie.zerulla@schering.de (M. Zerulla). 


\section{Introduction}

Concern regarding the potential endocrine modulating effects of environmental chemicals on human and wildlife health has existed for over 60 years. Indeed, endocrine modulating substances are of high ecotoxicological relevance, due to their potential adverse influence on the reproduction of organisms and consequently, on the existence of whole populations. In the late 1930s and early 1940s it was demonstrated that the gonadal sex of fish can be influenced by the administration of hormones. With the enormous expansion of fish culture in the past 25 years, it soon became apparent that it would be desirable to enhance the expression of a specific sex having advantages under certain culture strategies (Schreck, 1974; Donaldson and Hunter, 1982). For example estrogenic chemicals have been applied for purposes of controlled sex differentiation to at least 56 different species of teleosts belonging to 24 different families (Piferrer, 2001). Thus, aquaculture has provided proof that gonadal sex of fish, and thus, reproduction and population dynamics, can be manipulated by endocrine modulating substances, whether they be genuine hormones or not. Thus, it should not have come as a surprise that reports regarding dysregulation of sexual development and reproduction in wildlife populations soon became more frequent, e.g. masculinisation phenomena in conjunction with tributyltin exposure in prosobranchs, imposex phenomena in marine and freshwater snails (Langston, 1996; Oehlmann et al., 1996) or the feminisation of British fish downstream of sewage treatment plants (Jobling and Sumpter, 1993; Purdom et al., 1994; Harries et al., 1999). Furthermore, masculinising effects of pulp and paper mill effluents were observed in female mosquito fish (Gambusia affinis sp.) from NorthAmerican and New Zealand (Howell et al., 1980; Munkittrick et al., 1991, 1992; Parks et al., 2001; Ellis et al., 2001). A number of different in vivo and in vitro test systems e.g. estrogen/androgen receptor transfected cell lines (e.g. Petit et al.,
1997), receptor binding assays (e.g. Danzo, 1997) or in vivo assays in mammalians (e.g. Uterotrophic or Herschberger assay) and other vertebrates, were adopted to screen for the endocrine modulating activity of chemicals. The specification of the respective test systems and the quantification of the effects however, all have a different quality and therefore, the relevance of these tests systems for extrapolation to the environment and for risk characterisation are also highly variable.

One measure of estrogenic activity is the production of vitellogenin (VTG), an estrogen-inducible egg-yolk protein precursor. This protein, normally synthesised in the liver of female oviparous vertebrates, is estrogen dependent and increases markedly in the serum during oocyte development (Folmar et al., 1996). In general the VTG gene is present but only marginally expressed in males or juveniles (Tyler et al., 1999).

VTG can be determined, in vivo and in vitro, either following exposure of cells or whole animals to endocrine active substances (Jobling and Sumpter, 1993; Harries et al., 1999). Meanwhile the demonstration of a VTG increase is considered to be an 'evidence' for estrogen activity (Fent et al., 1996; Bjerregaard et al., 1998). However, there is a lack of understanding about changes of VTG levels following exposure to endocrine modulating substances with other modes of action like androgens or anti-estrogens. The European Chemical Industry's aquatic research programme for endocrine disrupters includes the development of an in vivo screening assay with juvenile fish. Nine chemicals, with different endocrine modulating activities were used to develop the screening protocol, among others methyltestosterone (MT) and fadrozole, (F) were chosen (for the other substances see Panter et al., 2002).

The aim of this study was to detect the effects of an androgen (MT) or an aromatase inhibitor F as well as the combination of MT and F on the expression and synthesis of VTG in sexually undifferentiated juvenile fathead minnows (Pimephales promelas). 


\section{Materials and methods}

\subsection{Test animals}

Juvenile, sexually undifferentiated fathead minnows ( $P$. promelas), between 2 and 3 months of age and with a total length of approximately $15 \pm 5 \mathrm{~mm}$, were employed. The juveniles were bred and cultured in the ecotoxicology laboratory at Schering AG (Berlin, Germany). The culture conditions were based on guidelines issued by the US Environmental Protection Agency (EPA, 1993). Every group of fish was acclimated for a minimum of 14 days, prior to the start of each experiment.

The fish were fed throughout the studies from the same batch of pelleted diet, known to be free of estrogenic activity (Trouw, UK; Preston, UK). The feeding rate was $1 \%$ of body weight twice a day (based on mean body weight on day 0 ).

\subsection{Exposure protocol}

All tests were conducted according to the OECD Principles of Good Laboratory Practice (GLP) and following the OECD guideline for testing of chemicals 204 .

\subsubsection{Test chemicals}

MT was purchased from Sigma Aldrich (Deisenhofen, Germany), F was a gift from Novartis (Basel, $\mathrm{CH}$ ), ethinylestradiol (EE2) was from Schering AG (Berlin, Germany). Purity of the chemicals was $>99 \%$.

\subsubsection{Dilution water}

Tap water (total hardness $258 \mathrm{mg} \mathrm{CaCO}_{3}$ per 1, conductivity $736 \mu \mathrm{s} / \mathrm{cm}$, dissolved organic carbon $3.7 \mathrm{ppm}$ ) from the municipal water supply in Berlin, Germany was used as dilution water. The water is routinely tested and was found to be free of chlorine and heavy metal residues. No further treatment of the water was necessary. The water was fed into a header tank from which it was pumped to the dilution water system at a constant pressure. It has been demonstrated to be suitable for the holding of fathead minnows during several years in the routine laboratory testing and culturing of fish.

\subsubsection{Exposure}

Prior to each study a range-finding study was carried out. No mortality or abnormal effects were observed up to nominal $100 \mu \mathrm{g} / 1$ for MT and F. For the definitive tests the following concentrations were used: 10,50 and $100 \mu \mathrm{g} / 1$, and 25,50 and $100 \mu \mathrm{g} / 1$ for $\mathrm{MT}$ and F, respectively. In the combination test 10 and $50 \mu \mathrm{g} / \mathrm{l}$ of $\mathrm{MT}$ and $\mathrm{F}$, respectively, were used. Additionally, a positive control (EE2 at nominal concentration of $10 \mathrm{ng} /$ 1), a dilution water control (DWC) and a solvent control (SC, $31 \mathrm{mg}$ dimethylformamid per 1 test solution resulted in the tanks) were employed in the MT and the combination test.

The studies were conducted in a flow through system.

Stock solutions of each chemical were prepared freshly prior to the start of every experiment. The substances were dissolved in tap water, apart from MT, and MT and F in the combination test, were the solvent dimethylformamid was used. The resulting concentration of the solvent was $31 \mathrm{mg} / 1$ test solution for the SC and the test formulations. These stock solutions were pumped continuously into a mixing chamber, where they were mixed with dilution water. The outflow of the mixing chamber was split into two 101 fish tanks, every duplicate with a flow through rate of $41 / \mathrm{h}$. The combination test was not run in duplicate, and the flow through rate was $8 \mathrm{l} / \mathrm{h}$. A photoperiod of 16:00 h light and 08:00 h darkness was provided.

Three days prior to the fish were exposed, dosing commenced to saturate the system with the test substance. Each exposure vessel was made of glass and contained initially 68 juvenile fathead minnows. For the combination study (MT and F), only a single system with 36 juveniles was established. The fish were exposed for 21 days, in the combination study (MT and F) for 14 days. All studies were carried out consecutively with separate controls.

\subsection{Measurements}

\subsubsection{Physico-chemical measurements and biological observations}

Physico-chemical parameters were determined daily, $\mathrm{pH}$ and oxygen saturation ranged between 
7.7-8.1 and 7.6-8.2 $\mathrm{mg} / \mathrm{l}$, respectively, throughout the whole exposure period. The temperature was equilibrated at $25 \pm 2{ }^{\circ} \mathrm{C}$ throughout the exposure periods.

Mortalities and abnormal behaviour were recorded daily and dead fish were removed from the tanks. On day 4, 7, 14 and 21, 17 fish per replicate were randomly sampled and humanely sacrificed (according to German Animal Welfare Regulations). In the $\mathrm{MT}+\mathrm{F}$ combination study 12 fish were taken on day 4,7 and 14. Total length and the wet weight were determined. Subsequently individual fish were transferred into labelled eppendorf $\left.{ }^{(}\right)$tubes, frozen and stored at $-20{ }^{\circ} \mathrm{C}$ for homogenisation and VTG analysis.

\subsubsection{Analytical chemistry}

From each test vessel (both replicates), $500 \mathrm{ml}$ samples of the test or control water were taken on day $0,4,7,14$, and 21 (no samples were taken from the combination test). Sample bottles were pre-incubated for $30 \mathrm{~min}$ with the water sample to saturate the bottles, the sample water discarded and then refilled with fresh water sample. Chemical analyses of the test concentrations in the respective water samples were carried out for each replicate of the treatment groups, SC and control for each sampling point. Concentrations of MT were analysed by radioimmunoassay, concentrations of $\mathrm{F}$ were determined by high performance liquid chromatography and UV detection.

\subsubsection{VTG enzyme linked immunosorbant assay (ELISA)}

After thawing the fish $(n=32$ per group and sampling day and $n=10$ in the combination test), VTG measurement was carried out according to Panter et al. (2002) in whole body homogenates of the fish using a procedure adapted from Tyler et al. (1999).

\subsubsection{Reverse transcription-polymerase chain reaction ( $R T-P C R)$}

Total RNA was isolated from the remaining whole, pulverised fish ( $n=2$ per group and sampling day) with a phenol/chloroform extraction using TRIzol ${ }^{\text {TM}}$-Reagent (Chomczynski and Sacchi, 1993). RNA was transcribed to cDNA (reverse transcription) followed by PCR (35 cycles) with primer for VTG, estrogen receptor (ER) and $\alpha$-Actin, as a housekeeping gene. Further details of the primer sequences and method can be obtained from the corresponding author of this paper.

\subsubsection{Statistics}

Wet weights, total length and VTG concentrations (original data) were analysed by analysis of variance (ANOVA). Where the assumptions of normality and homogeneity of variance were met, ANOVA was followed by a Dunnett's test (two sided) to compare the treatment means with respective controls. Where the assumptions were not met data were analysed using a suitable non-parametric test (Wilcoxon's Rank Sum, Sokal and Rohlf, 1981). Statistical comparisons with the control were made using the DWC, however, when both a SC and a DWC were present, the SC was used as the overall control. The results are reported as mean \pm standard deviation (S.D.). Concentration related responses were determined using a linear regression statistical package (Dunnett, 1964).

\section{Results}

\subsection{Test solution analyses}

Mean actual concentrations analysed are given in Table 1. The concentrations in the combination test were not determined. The mean measured concentration of the EE2 positive control was $5.2 \mathrm{ng} / 1$ and determined in the $\mathrm{F}$ study, only. Although the mean concentrations analysed were below (MT) or higher (F) than nominal concentrations intended, no systematic error in weighing could be identified. In view of the fact that the actual concentrations followed the dose response as intended, the measured concentrations were considered acceptable. For the MT and F studies values are reported as actuals, whereas for the combined study nominals are used. 


\subsection{Mean body weight and total length}

Mean body weight and length data are presented in Table 2.

MT exposed fish showed a significant $(P \leq$ 0.05 ) increase in wet weight and total length on day 7 in the 10, $100 \mu \mathrm{g} \mathrm{MT/L}$ and EE2 positive control) compared with the SC (Table 2). However, due to the lack of a dose- and temporal related response, these effects were not considered as being compound related.

Length and weight was not affected by any of the test substances, indicated by a lack of a concentration related suppression or amplification at each sampling occasion. However, it appeared that it was extremely difficult to obtain representative samples of the fish populations at each sampling occasion, since the fish weight and length did not continuously increase as expected. Only in the F experiment there was a time dependent increase at all concentrations.

\subsection{Sex ratio of untreated fish}

On day 0 ( $=$ start of exposure) one group of 40 non-treated sexually undifferentiated juveniles were randomly selected out of each of the two batches of acclimated juveniles and held under the same conditions until the fish showed secondary sex characteristics ( $>6$ months), e.g. the black dorsal fin, the tubercles and an aggressive behaviour for the male fish. After sacrificing the surviving fish in MS222 (300 mg/l) the sex ratio was determined macroscopically.

For each batch of fish the sex ratio was nearly 1:1 (19 female to 21 male, or 18 female to 20 male).

\subsection{Mortality}

In Table 3, mortality of each test is summarised.

In none of the treatment groups $>10 \%$ mortality was recorded (Table 3). Exposure to 29.5 and $52.4 \mu \mathrm{g} / 1 \mathrm{MT}$ produced a slight increase in mortality when compared with the lower dose, SC and control group. In addition, many fish in the MT groups were cannibalised, such that not all fish were accounted for at the end of the study. Because of this no statistically analysis of the last sampling day (day 21) of this study can be done.

\subsection{VTG levels in whole body homogenates}

VTG levels were determined in whole body homogenates, as the amount of blood necessary for VTG determination in plasma samples could not be obtained from such juvenile fish employed here.

A sub-sample of 32 and ten untreated fish from the MT and F studies and the MT and F combination test, respectively, were sampled to obtain baseline levels of VTG in whole body homogenate, body weight and total length of the fish

Table 1

Nominal vs. mean measured concentration for the three different studies

\begin{tabular}{llcc}
\hline Study & Chemical & Nominal concentration $(\mu \mathrm{g} / \mathrm{l})$ & Mean measured concentration $(\mu \mathrm{g} / \mathrm{l} \pm \mathrm{S} . \mathrm{D})$. \\
\hline MT test & MT & 10.0 & $6.9 \pm 0.8$ \\
& & 50.0 & $29.5 \pm 3.1$ \\
& & 100.0 & $52.4 \pm 10.5$ \\
F test & F & 25.0 & $37.7 \pm 3.1$ \\
& & 50.0 & $87.4 \pm 2.4$ \\
Combination test & MT & 100.0 & $114.6 \pm 1.4$ \\
& F & 50.0 & n.d. \\
& MT $+F$ & $10.0+50.0$ & n.d. \\
\hline
\end{tabular}

n.d., Not determined; S.D., standard deviation. 
Table 2

Mean body weight and total length of the exposed fish

\begin{tabular}{|c|c|c|c|c|c|}
\hline $\begin{array}{l}\text { Nominal concentration } \\
(\mu \mathrm{g} / \mathrm{l})\end{array}$ & $\begin{array}{l}\text { Day } 0 \text { untreated } \\
\text { fish }^{\mathrm{a}}\end{array}$ & $\begin{array}{l}\text { Day } 4(\mathrm{mg}) \\
(\mathrm{mm})^{\mathrm{a}}\end{array}$ & $\begin{array}{l}\text { Day } 7(\mathrm{mg}) \\
(\mathrm{mm})^{\mathrm{a}}\end{array}$ & $\begin{array}{l}\text { Day } 14(\mathrm{mg}) \\
(\mathrm{mm})^{\mathrm{a}}\end{array}$ & $\begin{array}{l}\text { Day } 21(\mathrm{mg}) \\
(\mathrm{mm})^{\mathrm{a}}\end{array}$ \\
\hline \multicolumn{6}{|c|}{ MT test $(n=32$, day $21 n=3-12)$} \\
\hline \multirow[t]{2}{*}{$0.0(\mathrm{C})$} & $80.4 \pm 82.9$ & $25.8 \pm 13.1$ & $27.9 \pm 24.3$ & $65.3 \pm 38.4$ & $65.1 \pm 57.4$ \\
\hline & $15.8 \pm 3.6$ & $11.3 \pm 2.3$ & $11.2 \pm 2.8$ & $14.7 \pm 2.8$ & $14.1 \pm 3.3$ \\
\hline \multirow[t]{2}{*}{$0.0(\mathrm{SC})$} & & $41.2 \pm 46.2$ & $35.5 \pm 32.2$ & $160.3 \pm 136.1$ & $84.7 \pm 141.4$ \\
\hline & & $11.5 \pm 4.0$ & $12.3 \pm 2.8$ & $18.1 \pm 5.2$ & $14.2 \pm 5.5$ \\
\hline \multirow[t]{2}{*}{10.0} & & $57.2 \pm 43.2$ & $79.9 \pm 113.9$ & $138.1 \pm 135.3$ & $210.5 \pm 163.3$ \\
\hline & & $13.7 \pm 3.5$ & $14.6 \pm 4.1$ & $17.5 \pm 45.7$ & $20.5 \pm 5.0$ \\
\hline \multirow[t]{2}{*}{50.0} & & $40.8 \pm 49.5$ & $65.2 \pm 92.5$ & $97.3 \pm 100.3$ & $30.5 \pm 17.7$ \\
\hline & & $12.0 \pm 4.0$ & $13.3 \pm 4.4$ & $14.8 \pm 4.1$ & $12.5 \pm 0.7$ \\
\hline \multirow[t]{2}{*}{100.0} & & $40.9 \pm 41.1$ & $69.1 \pm 139.3$ & $129.8 \pm 105.1$ & $133.0 \pm 132.9$ \\
\hline & & $12.5 \pm 3.6$ & $14.3 \pm 4.9$ & $16.9 \pm 4.4$ & $16.5 \pm 5.0$ \\
\hline \multirow[t]{2}{*}{ EE2 } & & $47.3 \pm 49.0$ & $69.1 \pm 61.2$ & $96.0 \pm 68.4$ & $56.3 \pm 48.0$ \\
\hline & & $12.5 \pm 3.6$ & $14.3 \pm 3.6$ & $15.9 \pm 3.1$ & $13.2 \pm 3.7$ \\
\hline \multicolumn{6}{|l|}{$F$ test $(n=32)$} \\
\hline \multirow[t]{2}{*}{$0.0(\mathrm{C})$} & $73.2 \pm 56.9$ & $51.5 \pm 30.2$ & $140.3 \pm 87.1$ & $170.5 \pm 88.2$ & $200.9 \pm 115.3$ \\
\hline & $15.1 \pm 3.1$ & $14.2 \pm 2.4$ & $12.9 \pm 2.4$ & $19.0 \pm 3.1$ & $20.0 \pm 4.4$ \\
\hline \multirow[t]{2}{*}{25.0} & & $53.4 \pm 45.3$ & $137.8 \pm 87.0$ & $139.1 \pm 79.4$ & $193.5 \pm 86.0$ \\
\hline & & $13.8 \pm 3.4$ & $17.2 \pm 3.9$ & $17.8 \pm 3.2$ & $19.7 \pm 3.1$ \\
\hline \multirow[t]{2}{*}{50.0} & & $51.6 \pm 38.6$ & $68.5 \pm 48.2$ & $140.8 \pm 72.7$ & $225.1 \pm 107.6$ \\
\hline & & $13.3 \pm 3.1$ & $13.5 \pm 3.5$ & $18.4 \pm 3.2$ & $20.4 \pm 3.7$ \\
\hline \multirow[t]{2}{*}{100.0} & & $53.7 \pm 37.8$ & $97.0 \pm 62.5$ & $140.2 \pm 67.6$ & $185.3 \pm 109.7$ \\
\hline & & $14.9 \pm 3.0$ & $16.6 \pm 3.2$ & $18.9 \pm 3.2$ & $20.5 \pm 4.0$ \\
\hline \multirow[t]{2}{*}{ EE2 } & & $59.3 \pm 43.0$ & $93.7 \pm 58.4$ & $112.2 \pm 63.0$ & $153.2 \pm 89.7$ \\
\hline & & $15.3 \pm 3.2$ & $15.6 \pm 3.7$ & $17.5 \pm 3.4$ & $19.2 \pm 3.8$ \\
\hline \multicolumn{6}{|l|}{ Combination test $(n=10)$} \\
\hline \multirow[t]{2}{*}{$0.0(\mathrm{SC})$} & $84.8 \pm 62.5$ & $45.1 \pm 41.5$ & $175.5 \pm 132.5$ & $162.6 \pm 109.6$ & - \\
\hline & $14 \pm 3$ & $12 \pm 4$ & $19 \pm 5$ & $19 \pm 5$ & \\
\hline $10.0(\mathrm{MT})$ & & $\begin{array}{c}176.9 \pm 181.2 \\
17 \pm 6\end{array}$ & $\begin{array}{c}154.1 \pm 124.5 \\
18 \pm 5\end{array}$ & $\begin{array}{c}162.8 \pm 127.2 \\
16 \pm 6\end{array}$ & - \\
\hline $50.0(\mathrm{~F})$ & & $\begin{array}{c}57.9 \pm 62.9 \\
14 \pm 3\end{array}$ & $\begin{array}{l}80.9 \pm 66.3 \\
15 \pm 5\end{array}$ & $\begin{array}{c}139.1 \pm 129.4 \\
17 \pm 6\end{array}$ & - \\
\hline $10.0(\mathrm{MT})+50.0(\mathrm{~F})$ & & $\begin{array}{c}35.7 \pm 33.7 \\
12 \pm 4\end{array}$ & $\begin{array}{c}77.8 \pm 109.8 \\
14 \pm 4\end{array}$ & $\begin{array}{l}201.8 \pm 159.2 \\
21 \pm 5\end{array}$ & - \\
\hline
\end{tabular}

${ }^{\text {a }}$ Representing individual batches of fish, randomly selected from the exposure tanks at the respective days.

at the start of the experiment (= day 0$)$, the VTG levels of these fish were not shown in the figures.

\subsubsection{Methyltestosterone}

A time dependent increase in VTG concentrations was observed in fish exposed to MT (Fig. 1). Fathead minnows exposed to $6.9 \mu \mathrm{g}$ MT per 1 for 4 days had VTG concentrations more than 4.6fold higher than fish of the SC (1301 vs. 280 $\mu \mathrm{g} / \mathrm{ml}$, respectively). At day 14 the VTG concentrations in, MT-exposed fish had increased to more than $9000 \mu \mathrm{g} / \mathrm{ml}$ in all exposure concentra- tions. For all time points and in each treatment group the increase was significant $(P \leq 0.05)$, compared with the SC.

\subsubsection{Fadrozole}

A decrease in whole body VTG concentrations was observed in fish exposed to F (Fig. 2). This decrease was significant $(P \leq 0.05)$ only in the 87.7 $\mu \mathrm{g} F$ per 1 group at day 7 and 14 , and in the 114.6 $\mu \mathrm{g} F$ per 1 group at day 14 . However, it was neither concentration nor time dependent. VTG was detectable in all fish (exposed and control). 


\subsubsection{Combination test}

For the combined testing of F and MT both substances were dissolved in dimethylformamide (31 mg DMF per 1) and no water (DWC) or positive (EE2) control was tested. For comparison of VTG concentrations in exposed fish, fish from the SC were taken (Fig. 3). The simultaneous exposure to $\mathrm{F}$ and $\mathrm{MT}$ had no significant effect on whole body VTG concentrations.

\subsection{VTG and ER gene expression}

\subsubsection{Methyltestosterone}

The present data suggests that exposure of fathead minnows to MT leads to a de novo synthesis of VTG mRNA as of day 4. Juveniles from the positive control (nominal $10 \mathrm{ng}$ EE2 per 1) demonstrated a similar increase in VTG mRNA. Unfortunately, RNA isolation from the day 14 samples was unsuccessful, e.g. only very faded bands for $\alpha$-actin and no bands of VTG were visible, respectively. Similarly only one fish of the positive control presented with a strong expression. Exposure of juveniles to MT had no effect on the ER expression (Fig. 4a).

\subsubsection{Fadrozole}

No VTG mRNA was detectable in the control fish or in the $F$ exposed juveniles, at all sampling time points. However, no VTG expression was detectable in the EE2 exposed fish (corresponding positive control). Actin bands were detectable in all samples. Weak bands from day 7 and 21 EE2 exposed fish (positive control) suggested that some of the RNA had denatured prior to submission to RT-PCR. Only very poor bands were detected for the ER in all juveniles (control or exposed), thus, no conclusions could be drawn from these bands (Fig. 4b).

\subsubsection{Combination test}

No expression of VTG mRNA could be detected in the MT and F combination test, whereas, as expected from the previous experiments, the MT exposed fish showed a strong

Table 3

Mortality for each test, $n=136(\mathrm{MT}+\mathrm{F}), n=36$ (combination test)

\begin{tabular}{|c|c|c|c|c|c|}
\hline Exposure nominal $(\mu \mathrm{g} / \mathrm{l})$ & First week & Second week & Third week & Total (number) & Total $(\%)$ \\
\hline \multicolumn{6}{|l|}{$M T$} \\
\hline $\mathrm{C}$ & 2 & 1 & 1 & 4 & 2.9 \\
\hline $\mathrm{SC}$ & - & 1 & - & 1 & 0.7 \\
\hline 10.0 & - & 1 & 3 & 4 & 2.9 \\
\hline 50.0 & 3 & 1 & 3 & 7 & 5.1 \\
\hline 100.0 & 2 & 4 & 1 & 7 & 5.1 \\
\hline EE2 & 2 & - & - & 2 & 1.5 \\
\hline \multicolumn{6}{|l|}{$F$} \\
\hline $\mathrm{C}$ & - & - & - & - & 0 \\
\hline 25.0 & - & - & 1 & 1 & 0.7 \\
\hline 50.0 & - & - & - & - & 0 \\
\hline 100.0 & 1 & 1 & - & 2 & 1.5 \\
\hline EE2 & 1 & - & 1 & 2 & 1.5 \\
\hline \multicolumn{6}{|l|}{ Combination } \\
\hline $\mathrm{SC}$ & - & - & - & - & 0 \\
\hline $10.0 \mathrm{MT}$ & - & - & - & - & 0 \\
\hline $50.0 \mathrm{~F}$ & - & - & - & - & 0 \\
\hline $\mathrm{MT}+\mathrm{F}$ & - & - & - & - & 0 \\
\hline
\end{tabular}




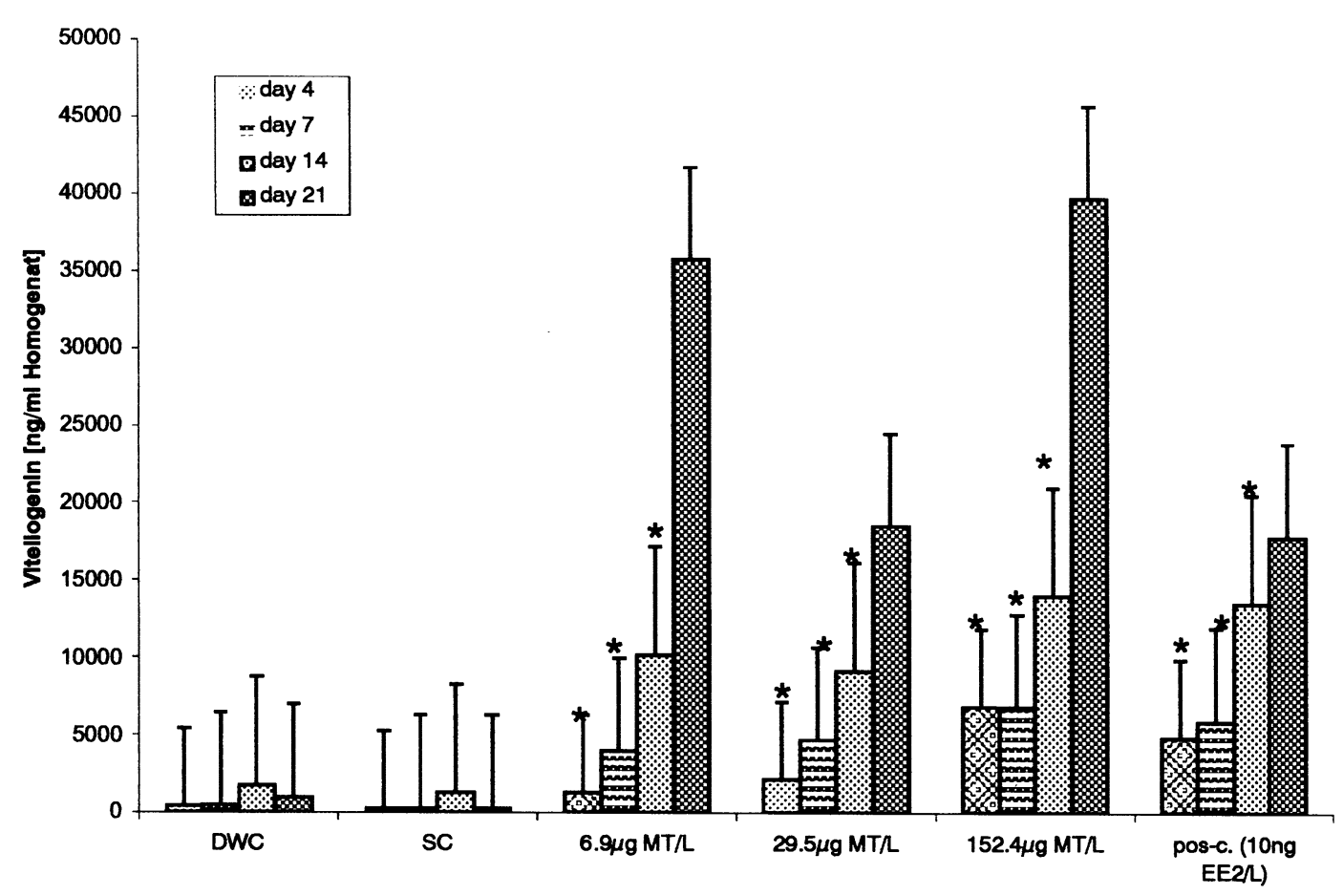

Fig. 1. Mean VTG levels in fish homogenate exposed to MT $(n=32$, day $21 n=3-12)$.

expression of VTG, while the fish from $\mathrm{F}$ and the SC were negative for VTG mRNA (Fig. 4c). Actin mRNA was detectable in samples of all groups. In contrast ER expression was too weak to derive any conclusions regarding possible changes in expression.

\subsection{Behaviour and sexual differentiation}

No behavioural changes (breathing, swimming and feeding) were observed in either the MT or F alone exposed, control and SC fish.

In contrast, fathead minnow juveniles exposed to MT and F combination demonstrated marked behavioural effects as of day 13 of exposure. These effects were characterised by heightened aggressiveness and marked territorial defence reactions. In addition, typical male sex characteristics, such as black dotted dorsal fins and nuptial tubercles, were observed in all treated fish. On day 14 all treated fathead minnows developed dark body coloration, a sign typical for fully sexual mature males. It is important to stress that the exposed fish were under 3 months of age, especially as under normal conditions such coloration effects appear after 6-7 months of age at the very earliest in our laboratory.

\section{Discussion}

The general aim of this study was the establishment of baseline data regarding VTG at the mRNA and protein level, in juvenile fathead minnows. In addition the question was asked whether juveniles would be suitable test organisms for screening of chemicals to be tested for hormonal activity.

The yolk protein VTG is a widely used surrogate parameter for the detection of exposure to estrogenic substances in vivo and in vitro (Folmar et al., 1996; Sumpter and Jobling, 1995). In order to study whether a VTG response can be measured also as a consequence of exposure to compounds displaying hormonal activity other than estrogenicity, juvenile fathead minnows were ex- 
posed to an androgen, an aromatase inhibitor, and to a combination of both.

MT was chosen as androgen because the methylgroup at the $\mathrm{C}_{17}$-atom makes it distinguishable from the endogenous testosterone for analytical purposes. $\mathrm{F}$ is a potent aromatase-inhibitor employed for treatment of ER-positive breast-cancer (Michaud and Buzdar, 1999).

Following exposure of fathead minnows to $\mathrm{F}$ a slight concentration dependent, significant $(P \leq$ $0.05)$ decrease of the whole body VTG levels, compared with the control (DWC) was observed in some of the treatment groups, but this decrease was accompanied by a time dependent increase of VTG per treatment group. This observation is corroborated by the fact that VTG in fathead minnows has a very long half-life (approximately 9 days; Craik, 1977). No de novo synthesis of VTG mRNA could be detected with the RT-PCR. Whether this is a right observation or due to an incomplete RNA isolation, is impossible to derive from the data present. Given as a single compound, no adverse effects on the growth, mortality, the behaviour or on general health of exposed fish could be observed over the whole exposure time.

Exposure of juvenile fathead minnows to MT produced no clear pattern as to body weight and length, i.e. the fish varied very strongly in their body weight, but not in length. Despite the weight variability, no compound related effect on growth could be detected, suggesting a lack of general non-specific toxicity at the test concentrations employed. In corroboration to this observation, MT (200 $\mu \mathrm{gMT}$ per 1) had no effects on growth in mud loach (Migurnus mizolepis; Nam et al., 1998).

Contrary to the expectation that MT would induce a masculinisation of juvenile fathead minnows, a significant $(P \leq 0.05)$ time and concentration dependent increase of VTG levels in the whole body homogenate became apparent. Indeed, MT was reported to induce masculinisation of various different fish species (Varadaraj et al., 1994; Blàzquez et al., 1995), e.g. $\geq 99.3 \%$ masculinisation in mud loach (M. mizolepis) fry to exposed 100 and $200 \mu \mathrm{g}$ MT per 1 (Nam et al., 1998). On the other hand, feminisation effects of MT were described for

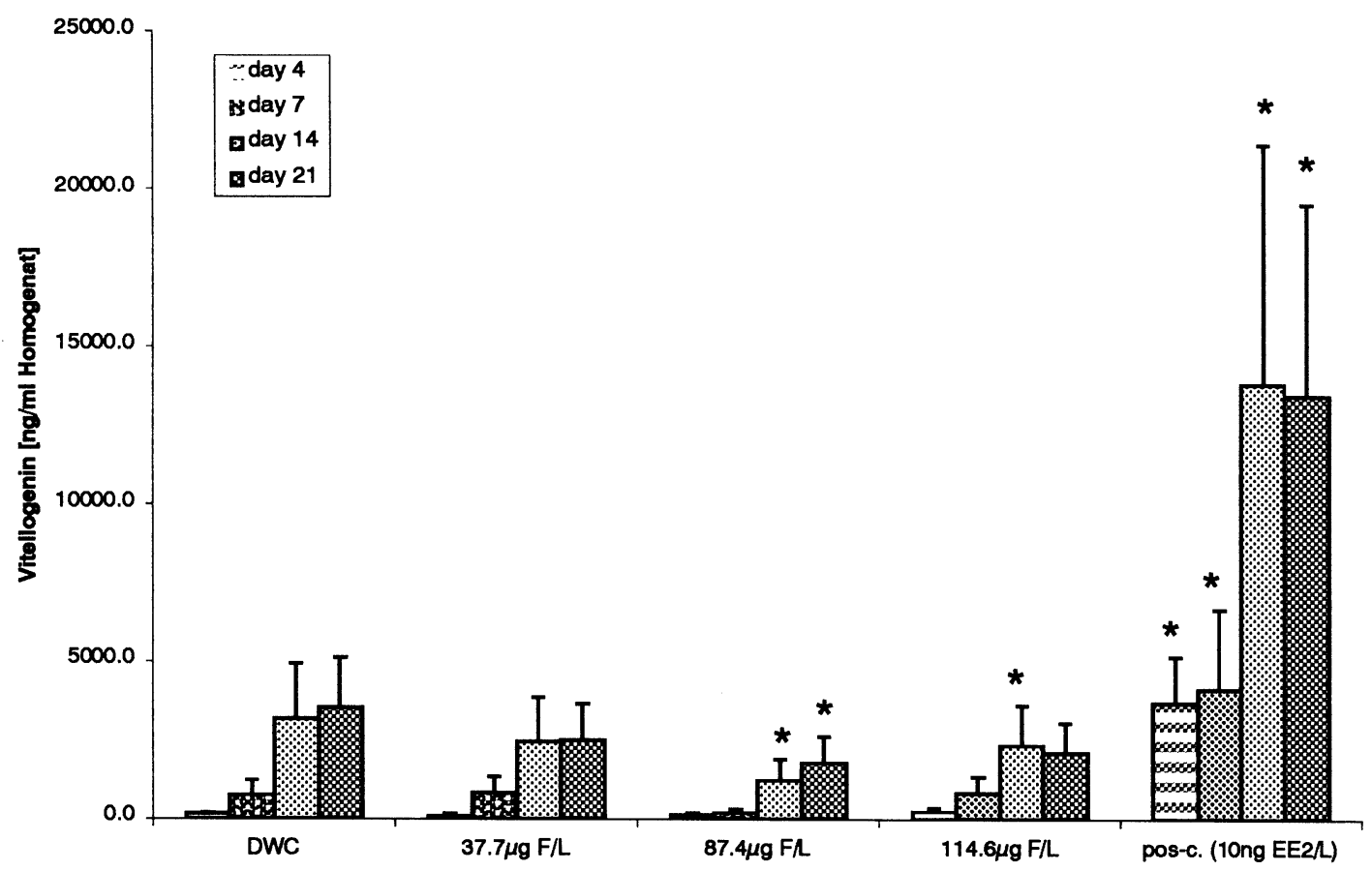

Fig. 2. Mean VTG levels in fish homogenate exposed to $\mathrm{F}(n=32)$. 


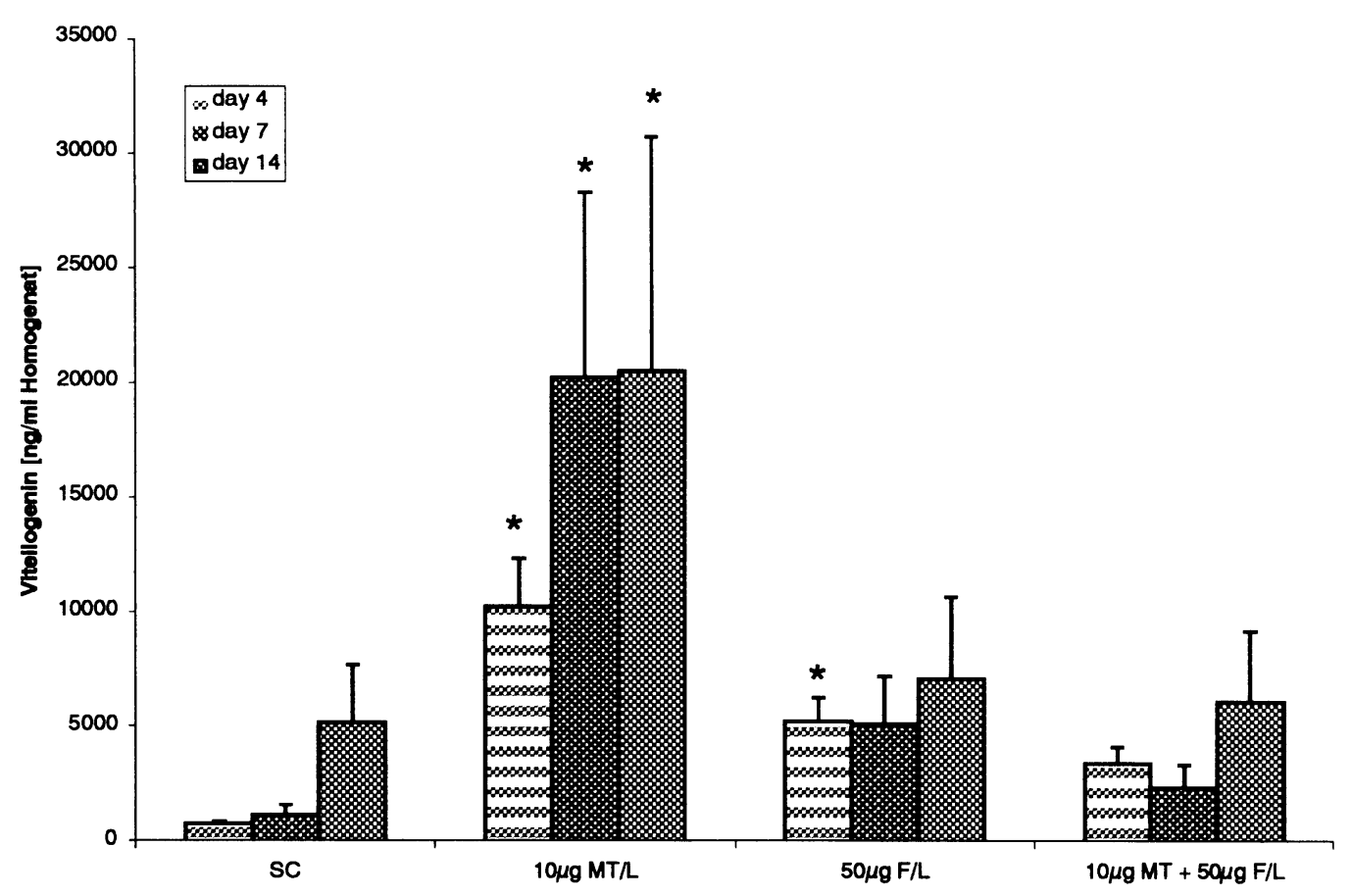

Fig. 3. Mean VTG levels in fish homogenate exposed in the combination test $(n=10)$.

goldfish (Hori et al., 1979) or cultured rainbow trout hepatocytes (Mori et al., 1998).

Ankley et al. (2001) demonstrated masculinisation in adult fathead minnows via a waterborne exposure to $200 \mu \mathrm{g}$ MT per 1, while simultaneously an increase in plasma VTG levels was observed. The data presented here corroborate these earlier findings in that with RT-PCR it was possible to detect a de novo synthesis of VTG mRNA in the MT exposed fish.

In view of these slightly contradictory observations, two hypotheses appeared as potential explanations for the MT dependent increase of whole body VTG levels: MT binds with low affinity to the ER and thus, activates VTG transcription. Or alternatively MT is converted through the endogenous aromatase to an estrogen which subsequently induced VTG transcription.

Consequently, the combination test, simultaneously exposing juvenile fathead minnows to MT and $\mathrm{F}$, was conducted in order to evaluate the latter two hypotheses. Direct binding of MT to the ER should lead to the same VTG increase in exposure settings with and without $\mathrm{F}$ present. On the other hand the inhibition of the aromatisation of MT with F should lead to a decrease or stagnation of VTG levels under the combinatorial exposure conditions.

The results under the combination exposure conditions strongly suggested that MT can be aromatised to an estrogen, since no VTG increase was observed. On the contrary, all exposed fish in the combination group showed premature secondary male sex characteristics, such as a pigmented dorsal fin, tubercles or aggressive territory defence. Furthermore, only the MT exposed fish showed a de novo synthesis of VTG mRNA in the RT-PCR, but not the $F$ exposed fish or the fish of the combination group.

This leads to the presumption, that waterborne MT was incorporated and converted in fathead minnows through an endogenous aromatase to an estrogen, e.g. to methylestradiol (pers. Commun. D. Kime). Accordingly, exposure to MT leads to a partial feminisation of the exposed fathead minnows, while in combination with the aromatase-inhibitor F MT was able to exert its full androgenic potential. 
The comparison of published data on effects of MT in fish (masculinisation after MT exposure: mozambique tilapia, Varadaraj et al., 1994 sea bass Blàzquez et al., 1995 mud leach Nam et al., 1998, masculinisation with VTG increase: fathead minnow, Ankley et al., 2001, feminisation after MT exposure: goldfish, Hori et al., 1979 and rainbow trout hepatocytes, Mori et al., 1998) suggests that the prevalence of either feminisation or masculinisation is species and age specific. Possibly the aromatase activity, specificity, or expression levels vary in different species and in the different stages of maturation. However, the present data strongly depict that hormonal active substances affect the phenotype by interfering with the process of sexual differentiation, by promoting or inhibiting the expression of certain genes.
In conclusion, the present experiments demonstrated, that changes in VTG concentrations are measurable in mixed sex juvenile fathead minnows at the mRNA and protein level. VTG concentrations not only increase following exposure to classic estrogens, but also following exposure to an aromatisable androgen. It was also shown, that under the influence of the aromatase inhibitor juvenile fathead minnows developed premature strong male secondary sexual characters, when co-exposed to MT. The morphological and behavioural changes were found to be an additional important endpoint in short-term tests for endocrine active substances with androgenic mechanisms, apart from VTG as biochemical marker. From these results it becomes evident, that additional parameters need to be identified and thoroughly tested for in vivo and in vitro

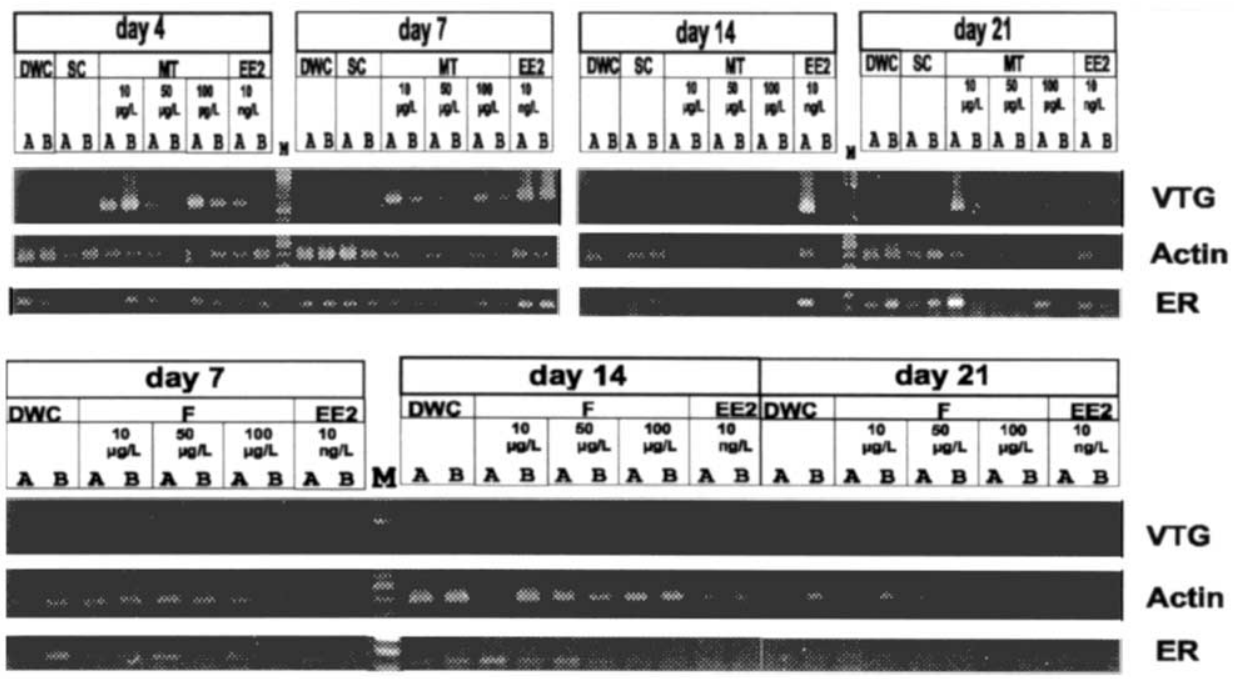

$4 \mathrm{~A}$

4B

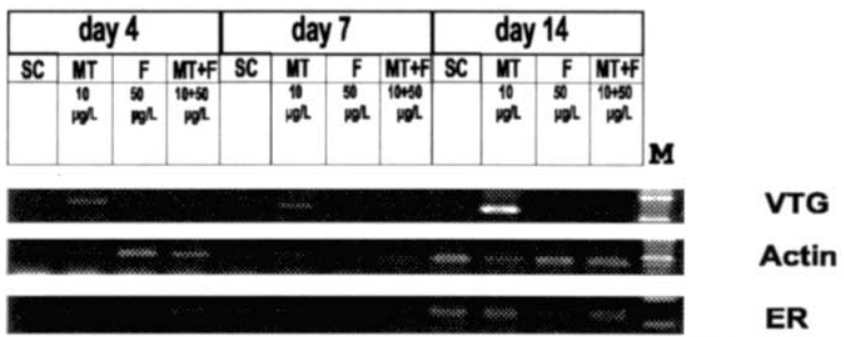

Fig. 4. Gel electrophoresis of the RT-PCR. A and B stands for the replicates and M for the marker, (A) MT study, (B) F study, (C) combination test. 
identification of potentially endocrine modulating substances, especially for androgens or antiandrogens.

\section{Acknowledgements}

Our thanks to Mirco Klein and all colleagues at the ecotoxicology and bioanalytic laboratory of the Schering AG. In addition, special thanks to the members of the environmental toxicology group of the University of Konstanz and David Kime (Sheffield University). Thanks to Novartis for the gift of F, to EMSG for co-funding the MT and $\mathrm{F}$ studies, also to ECETOC as they were the original authors for the concepts described here.

\section{References}

Ankley, G.T., Jensen, K.M., Kahl, M.D., Korte, J.J., Makynen, E.A., 2001. Description and evaluation of a shortterm reproduction test with the Fathead minnow (Pimephales promelas). Environ. Tox. Chem. 20, 12761290.

Bjerregaard, P., Korsgaard, B., Christiansen, L.B., Pedersen, K.L., Christensen, L.J., 1998. Monitoring and risk assessment for endocrine disruptors in the aquatic environment: a biomarker approach. Arch. Tox. Suppl. 20, 97-107.

Blàzquez, M., Piferrer, F., Zanuy, S., Carrillo, M., Donaldson, E.M., 1995. Development of sex control techniques for european Sea bass (Dicentarchus labrux L.) aquaculture: effects of dietary $17 \alpha$-methyltestosterone prior to sex differentiation. Aquaculture 135, 329-342.

Chomczynski, P., Sacchi, N., 1993. A reagent for the singlestep simultaneous isolation of RNA and proteins from cell and tissue samples. Biotechniques 15, 532-534.

Craik, J.C.A., 1977. Kinetic studies of vitellogenin metabolsim in the Elasmobranch Scyliorhinus canicula L. Comp. Biochem. Physiol. 61A, 355-361.

Danzo, B.J., 1997. Environmental xenobiotics may disrupt normal endorcrine function by interferring with the binding of physiological ligands to steroid receptors and binding proteins. Environ. Health Persp. 105, 294-301.

Donaldson, E.M., Hunter, G.A., 1982. Sex control in fish with paritcular refernce to salmonides. Can. J. Fish. Aquat. Sci. 39, 99-110.

Dunnett, C.W., 1964. New tables for multiple comparisons with a control. Biometrics 26, 482-491.

Ellis, R.J., van den Heuvel, M.R., Stuthridge, T.R., McCarthy, L.H., Ling, N., Hogg, I.D., Dietrich, D.R., 2001. Androgenic responses in two fish species following exposure to a New Zealand pulp and paper mill wastewaters. 60
(1), 771-771. Annual Meeting of the Society of Toxicology, San Francisco, USA, March 25-29, 2001, Toxicol. Sci.

EPA, 1993. Guideline fourth Edition. Methods for measuring the acute toxicity of effluents and receiving waters to freshwater and marine organisms. EPA /600/4-90/027F, 1-293. Washington, DC, 20460.

Fent, K., 1996. Endocrinically active substances in the environment: state of the art. Endocinically active chemicals in the environment. Texte Umweltbundesamt Berlin 3 (36), 69-80 UBA Berlin, Selbstverlag.

Folmar, L.C., Denslow, N.D., Rao, V., Chow, M., Crain, D.A., Enblom, J., Marcino, J., Guillette, L.J. Jr, 1996. Vitellogenin induction and reduced serum testosterone concentrations in feral male Carp (Cyprinus carpio) captured near a major metropolitan sewage treatment plant. Comp. Biochem. Physiol. 104, 1096-1101.

Harries, J.E., Janbakhsh, A., Jobling, S., Matthiessen, P., Sumpter, J.P., Tyler, C.R., 1999. Estrogenic potency of effluent from two sewage treatment works in the UK. Envrion. Tox. Chem. 18, 932-937.

Hori, S.H., Kodama, T., Tanahashi, K., 1979. Induction of vitellogenin synthesis in Goldfish by massive doses of androgens. Gen. Comp. Endocrinol. 37, 306-320.

Howell, W.M., Black, D.A., Bortone, S.A., 1980. Abnormal expression of secondary sex characterisics in a population of Mosquitofish, Gambusia affinis holbrooki: evidence for environmentally induced masculinization. Copeia 4, 676681.

Jobling, S., Sumpter, J.P., 1993. Detergent components in sewage effluent are weakly oestrogenic to fish: an in vitro study using Rainbow trout (Oncorhynchus mykiss). Aquat. Toxicol. 27, 361-372.

Langston, W.J., 1996. Recent developments in TBT ecotoxicology. Toxicol. Ecotoxicol. News 3, 179-187.

Michaud, L.B., Buzdar, A.U., 1999. Risks and benefits of aromatase inhibitors in postmenopausal breast cancer. Drug Saf. 21, 297-309.

Mori, T., Matsumoto, H., Yokota, H., 1998. Androgen-induced vitellogenin gene expression in primary cultures of Rainbow trout hepatocytes. J. Steroid Biochem. 67, 133141.

Munkittrick, K.R., Portt, C.B., van der Kraak, G., Smith, R.J., Rokosh, D.A., 1991. Impact of bleached kraft mill effluent on population characteristics, liver MFO activity, and serum steroid levels of a Lake Superior White Sucker (Catostomus commersoni) population. Can. J. Fish. Aquat. Sci. 48, 1371-1380.

Munkittrick, K.R., van der Kraak, G., McMaster, M.E., Portt, C.B., 1992. Response of hepatic MFO activity and plasma sex steroids to secondary treatment of bleached kraft pulp mill effluent and mill shutdown. Environ. Toxicol. Chem. 11, 1439.

Nam, Y.K., Noh, C.H., Kim, D.S., 1998. Effects of 17 alphamethyltestosterone immersion treatments on sex reversal of Mud loach, Migurnus mizolepis. Fish. Sci. 64, 914-917. 
Oehlmann, J., Stoben, E., Schulte-Oehlmann, U., Bauer, B., Fioroni, P., Markert, B., 1996. Tributyltin biomonitoring using Prosobranchs as sentinel organism. Fresenius J. Anal. Chem. 354, 540-545.

Panter, G.H., Hutchinson, T.H., Länge, R., Zerulla, M., Lye, C.M., Sumpter, J.P., Tyler, C.R., 2002. Utility of a juvenile Fathead minnow screening assay for detecting (anti-) estrogenic substances. Environ. Tox. Chem. 21, 319-326.

Parks, L.G., Lambright, C.S., Orlando, E.F., Guillette, L.J. Jr, Ankley, G.T., Gray, L.E. Jr, 2001. Masculinization of female Mosquitofish in kraft mill effluent-contaminated Fenholloway river water is associated with androgen receptor agonist activity. Toxicol. Sci. 62, 257-267.

Petit, F., Le Goff, P., Cravédi, J.-P., Valotaire, Y., Pakdel, F., 1997. Two complentary bioassays for screening the estrogenic potency of xenobiotics: recombinant yeast for trout estrogen receptor and trout hepatocyte cultures. J. Mol. Endocrinol. 19, 335.

Piferrer, F., 2001. Endocrine sex control strategies for the feminization of teleost fish. Aquaculture 197, 229-281.
Purdom, C.E., Hardiman, P.A., Bye, V.J., Eno, N.C., Tyler, C.R., Sumpter, J.P., 1994. Estrogenic effects of effluents from sewage treatment works. Chem. Ecol. 8, 275-285.

Schreck, C.B., 1974. Hormonal treatment and sex manipulation in fishes. In: Schreck, C.B. (Ed.), Control of Sex in Fishes. Virginia Polytechnic Institute and State University Sea Grant Program, pp. 84-106.

Sokal, R.R., Rohlf, F.J., 1981. Biometry: The Principals and Practice of Statistics in Biological Research. Freeman, New York.

Sumpter, J.P., Jobling, S., 1995. Vitellogenesis as a biomarker for estrogenic contamination of the aquatic environment. Environ. Health Persp. 103, 173-178.

Tyler, C.R., van Aerle, R., Hutchinson, T.H., Maddix, S., Trip, H., 1999. An in vivo testing system for endocrine disruptors in fish early life stages using induction of vitellogenin. Environ. Tox. Chem. 18, 337-347.

Varadaraj, K., Kumari, S.S., Pandian, T.J., 1994. Comparison of conditions for hormonal sex reversal of Mozambique tilapias. The Progressive Fish Culturist 56, 81-90. 